\title{
François-René de Chateaubriand, Correspondance générale
}

\section{Marika Piva}

\section{(2) OpenEdition}

1 Journals

\section{Edizione digitale}

URL: http://journals.openedition.org/studifrancesi/4392

DOI: 10.4000/studifrancesi.4392

ISSN: 2421-5856

\section{Editore}

Rosenberg \& Sellier

\section{Edizione cartacea}

Data di pubblicazione: 1 settembre 2016

Paginazione: 337-338

ISSN: 0039-2944

\section{Notizia bibliografica digitale}

Marika Piva, «François-René de Chateaubriand, Correspondance générale », Studi Francesi [Online], 179 (LX | II) | 2016, online dal 01 septembre 2016, consultato il 18 septembre 2020. URL : http:// journals.openedition.org/studifrancesi/4392 ; DOI : https://doi.org/10.4000/studifrancesi.4392

Questo documento è stato generato automaticamente il 18 settembre 2020.

\section{(c) (i) (9)}

Studi Francesi è distribuita con Licenza Creative Commons Attribuzione - Non commerciale - Non opere derivate 4.0 Internazionale. 


\title{
François-René de Chateaubriand, Correspondance générale
}

\author{
Marika Piva
}

\section{NOTIZIA}

FRANÇOIS-RENÉ DE CHATEAUBRIAND, Correspondance générale, tome IX, 1831-1835, textes réunis, établis et annotés par Agnès Kettler, Paris, Gallimard, 2015, 673 pp.

1 A cinque anni di distanza dalla pubblicazione del volume VIII della Correspondance générale di Chateaubriand esce il IX, il primo curato esclusivamente da Agnès Kettler che si basa sulla documentazione raccolta da Pierre Riberette, su fondi pazientemente e minuziosamente riordinati e arricchiti, su instancabili ricerche a tutto campo. L'impostazione rimane la medesima: un "Avant-propos» che traccia il quadro del periodo (i primi cinque anni della Monarchie de Juillet, in cui l'autore si erge come campione del movimento legittimista e delle libertà), una cronologia dettagliata, lettere e frammenti ordinati per data (665 in questo tomo), un'appendice (nel caso specifico alcune lettere della duchesse de Berry), il preciso e sobrio apparato di note con i necessari rinvii ai volumi precedenti, l'utilissima «Table des correspondants» che segnala se Chateaubriand ha già intrattenuto in precedenza scambi epistolari con la persona in oggetto.

2 Dalle pagine emergono gli spostamenti dell'autore delle Études historiques (pubblicate in aprile 1831) che non vuole «ni payer l'impôt à Louis-Philippe, ni vivre son sujet» (p. 96) e si esilia dunque a due riprese in Svizzera per dedicarsi alla stesura della sua autobiografia, quei Mémoires destinati a essere pubblicati solo dopo la sua morte come viene ripetuto incessantemente. D'altro canto gli avvenimenti lo ritrascinano sul campo di battaglia spingendolo a pubblicare quattro brochures (De la restauration et de la monarchie élective, marzo 1831; De la nouvelle proposition relative au bannissement de Charles X, ottobre 1831; Courtes explications sur les 12000 francs offerts par Mme la duchesse de Berry, aprile 1832; Mémoire sur la captivité de Mme la duchesse de Berry, novembre 1832), 
facendolo arrestare nel giugno 1832 e rimettendolo in viaggio l'anno successivo come porte-parole della madre di Henri V presso la famiglia reale esiliata a Praga. Com'è ben noto, è nel settembre del 1833 che Chateaubriand fa ritorno alla Serenissima cantata da Byron, soggiorno che ispirerà il celebre Livre sur Venise poi ridotto drasticamente nella versione definitiva dei Mémoires d'outre-tombe. Questi ultimi, ancora in fase di scrittura, sono nel corso del 1834 oggetto di letture nel salone dell'Abbaye-au-Bois, vera e propria operazione pubblicitaria sapientemente orchestrata e giustificata dal loro autore che si dichiara «curieux d'entendre quelques-uns des bruits qui ne [le] réveilleront pas dans [son] cercueil» (p. 310): è il via per diversi articoli, tra cui la celebre analisi di SainteBeuve, salutata come "un véritable chef-d'œuvre» (p. 320) da Chateaubriand. Nel frattempo quest'ultimo cerca di trovare una nuova collocazione per le sue Euvres complètes dopo il fallimento di Ladvocat, ma le negoziazioni sono complesse come evidenziano la lettera 488 «À un éditeur» e le missive inviate a Hyde de Neuville (492, $500,503)$. La rappresentazione del Moïse al teatro di Versailles è un fiasco come egli stesso aveva previsto (lettera 510 a Carmouche) e le impellenti difficoltà economiche lo obbligano a stipulare un contratto per l'Essai sur la littérature anglaise che servirà da introduzione alla sua traduzione del Paradise Lost di Milton (lettere 592, 603, 611, 654): occasione per inserire «quelques fragments de [ses] Mémoires» (p. 412).

3 Vita privata e pubblica risultano come sempre strettamente imbricate e fanno susseguire commenti caustici, riflessioni ad ampio raggio sulla situazione politica e culturale, il celebre stile incantatorio che si cristallizza in passi da antologia. Tanto nelle lunghe lettere quanto nei brevi messaggi, Chateaubriand spiega le proprie posizioni e le necessità che lo obbligano a prendere determinate decisioni, così come si scusa del ritardo delle sue risposte causato da motivi di salute o impegni di varia origine. Sorta di leitmotiv del primo gruppo di testi è il dispiacersi del fatto di essere costretto a dettare e non poter scrivere di proprio pugno a causa della gotta alla mano destra - le crisi di reumatismi accampate come giustificazione per la brevità delle missive sono ben note ai lettori della Correspondance -, mentre in seguito l'autore si dice obbligato a far ricopiare i propri testi indecifrabili e troppo voluminosi data la sua inconfondibile grafia.

4 Addentrandosi nel dedalo di lettere autografe, copie e frammenti, muovendosi tra $\mathrm{i}$ testi pubblicati nei giornali dell'epoca, quelli ripresi e rimaneggiati nei Mémoires, missive già note e altre completamente inedite, si seguono le vicende legate alla richiesta di poter essere seppellito nell'isolotto di fronte alla sua città natale (lettere 114 e 644 a Hovius, 606, 608 e 645 a La Morvonnais), si legge il noto testo indirizzato a Béranger che ha dedicato al nostro la canzone Chateaubriand pourquoi fuire ta patrie (lettera 99), si incappa in quell'Émile de Girardin (lettera 95) che acquisterà in seguito i diritti di pubblicare en feuilleton i Mémoires nella Presse. Per lo studioso dell'autobiografia la corrispondenza rimane uno strumento insostituibile che chiarifica o rettifica di volta in volta la versione postuma. Vi emergono tutte le grandi figure del periodo, quelle destinate a diventarlo, nonché personaggi meno conosciuti e oggi noti solo agli eruditi, che inviano i propri testi al sachem du Romantisme che non manca mai di ringraziare aggiungendo qualche commento elogiativo, ondeggiando tra formule di cortesia e sincero interesse (basti qui citare da un lato George Sand, dall'altro l'abbé Gervais de la Rue).

5 Nessun lettore può rimanere immune al fascino delle lettere inviate alle varie Mesdames che hanno punteggiato la vita di Chateaubriand e che in questo volume vedono 
aggiungersi quella che è stata «la passion complète de [sa] vie», «[sa] dernière muse, [son] dernier enchantement, [son] dernier rayon de soleil» (p. 188): Hortense Allart, «magicienne, volage, trompeuse et toujours aimée» (p. 185). Riappare l'occitanienne (Léontine de Villeneuve), la capricciosa Madame de Pierreclau è la destinataria di biglietti in cui si dichiara la volontà di rompere una relazione fatta «d'agitation et de querelle» (p. 175) e, dopo la lettera di insulti su Mme Récamier, le viene sistematicamente negata ogni possibilità di incontro. È Juliette la corrispondente a cui Chateaubriand invia il maggior numero di missive, ben 43; il breve soggiorno veneziano vede un curioso susseguirsi di testi all'amata e alla moglie in cui l'enchanteur rivela i suoi sogni di trasferirsi con entrambe nella città lagunare... Mme Récamier rimane, tra passioni subitanee e immancabili disillusioni, colei a cui scrivere "À vous seule, il appartient de chasser toutes ces fées de la forêt qui se sont jetées sur moi pour m'étrangler» (p. 366).

6 La prossima uscita della Correspondance générale dovrebbe essere il famigerato tomo VI, la pietra d'inciampo di questa pubblicazione monumentale iniziata nel 1977, che raccoglierà le missive relative al periodo in cui Chateaubriand fu ministro degli affari esteri (1 gennaio 1823-5 giugno 1824). Complicato insieme di dispacci pubblici e messaggi privati che gli chateaubriandisti aspettano con impazienza e che l'infaticabile Agnès Kettler condurrà sicuramente in porto. 